\title{
Form measurements of micro-holes
}

\author{
Chen-Chun Kao and Albert J Shih \\ Mechanical Engineering, University of Michigan, Ann Arbor, MI 48109-2125, USA
}

Received 11 June 2007, in final form 18 August 2007

Published 16 October 2007

Online at stacks.iop.org/MST/18/3603

\begin{abstract}
The form measurement and gauge repeatability and reproducibility (R\&R) of a micro-hole using a coordinate measurement machine (CMM) with a combination of optical and contact sensors were conducted in this study. The micro-holes, about $160 \mu \mathrm{m}$ in diameter and $0.9 \mathrm{~mm}$ in depth, were fabricated using the electrical discharge machining process for diesel fuel injectors. The shape and size of micro-holes are important for the desired spray pattern, fuel economy and exhaust emission of diesel engines. In this study, the setup of the measurement machine and the procedure to determine the contact points are presented. Five form characteristics, the cylindricity, diameter, roundness, straightness and taper, of the micro-hole are analyzed from measurement points. The gauge $R \& R$ test is conducted to determine the micro-hole form measurement capability and to calculate the tolerance specifications for each characteristic that the CMM is capable of measuring. An example to quantify the change in the shape of the micro-holes before and after the abrasive flow machining is presented.
\end{abstract}

Keywords: micro-hole measurement, gauge R\&R, coordinate measurement machine

(Some figures in this article are in colour only in the electronic version)

\section{Introduction}

Micro-holes, small holes with diameter less than $0.5 \mathrm{~mm}$ [1], have a wide range of applications, including ink-jet printer nozzles, orifices for bio-medical devices, cooling vents for gas turbine blade and diesel fuel injector spray holes. Microholes can be fabricated by electrical discharge machining (EDM) [2], laser drilling [3], electrochemical machining [4] or conventional drilling [5]. The micro-hole for a diesel engine fuel injector, as is illustrated in figure 1, is representative of a high volume production application. The size, shape, orientation, flow rate and surface roughness of the injector micro-hole are important to the spray pattern, fuel atomization and combustion, and emission of the diesel engine [6]. This research investigates the form measurement of $0.16 \mathrm{~mm}$ diameter fuel injector micro-holes.

EDM is the current production method to machine microholes for a diesel engine fuel injector [7, 8]. A solid schematic diagram of the EDM process for micro-hole drilling is illustrated in figure 2. A wire electrode is fed through a wire guide, which is made of ceramic for wear resistance, to drill a hole. Sparks at the tip of the wire electrode remove the work material and, subsequently, wear the electrode to create a rounded tip. The EDM micro-hole drilling process for a diesel injector was developed in the early 1970s when the heattreatment process was utilized to increase the material strength for high pressure fuel injection and emission reduction. Due to the stringent diesel emission regulations [9, 10], the form measurement of an injector micro-hole has become an important quality control tool that bridges the product design and manufacturing for diesel engine emission reduction.

Accurate form measurements of micro-holes are difficult due to the small diameter and high aspect ratio. State-of-theart injector micro-holes for on-highway truck diesel engines are usually 120 to $200 \mu \mathrm{m}$ in diameter and $1 \mathrm{~mm}$ in depth. A conventional coordinate measurement machine (CMM) and vision-based systems are not capable of form measurements of the micro-hole $[1,11,12]$. The micro-holes are currently evaluated using a destructive method [13] to cut hole crosssections and/or plastic molding to make a replica of microholes [7]. Both methods provide limited information on the form accuracy and dimension of micro-holes.

New micro-hole measurement methods were developed in the 1990s. The vibroscanning method, developed by Masuzawa's research group at the University of Tokyo, utilized the vibration of a thin probe to detect the contact and measure the form accuracy of micro-holes [1]. More advanced vibroscanning methods were developed to measure 


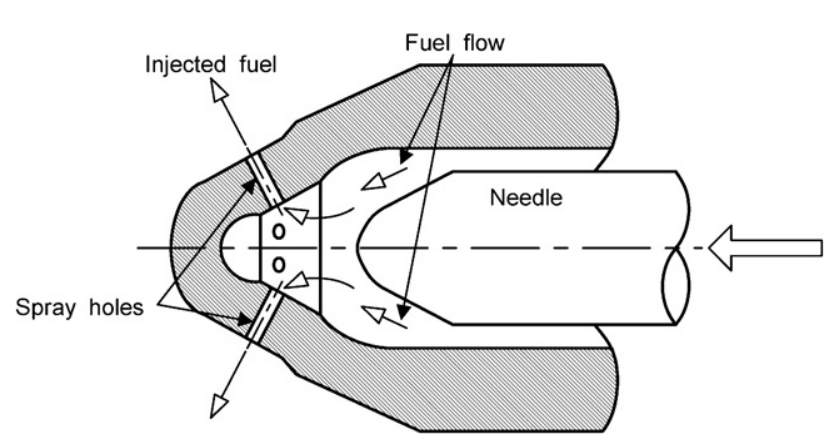

Figure 1. A schematic diagram of diesel fuel injector micro-holes of an injector nozzle, the needle and the fuel flow.

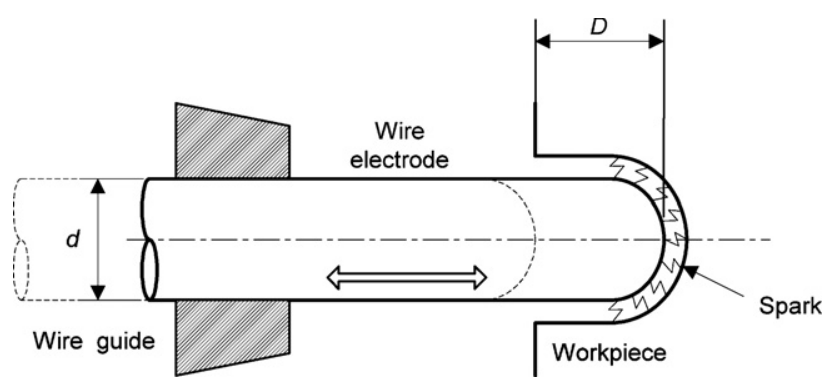

Figure 2. Micro-hole EDM using a wire electrode supported by a wire guide.

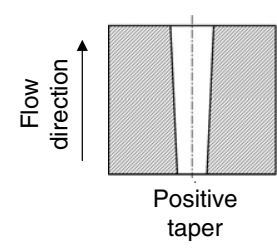

(a)

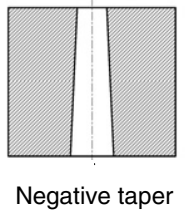

(b)

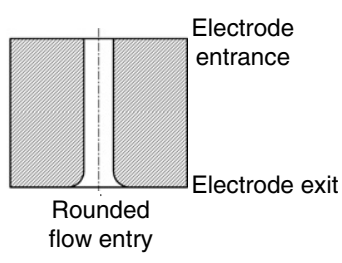

(c)
Figure 3. Classification of the shape of a micro-hole for the fuel injector: $(a)$ positive taper, $(b)$ negative taper and $(c)$ rounded flow entry.

the workpiece made of non-conductive materials [11, 12, 14-18]. Another method applies the combination of contact and non-contact (optical) sensors in a CMM. This technology, developed by Werth $\mathrm{GmbH}$ [19], is studied in this research for micro-hole measurement. The micro-hole shape measurement, gauge $R \& R$ and effect of the abrasive flow machining (AFM) on the shape and size of micro-holes are investigated.

Giedl et al [3] have classified the shape of a micro-hole: negative taper, positive taper and rounded flow entry, as is shown in figure 3. In EDM drilling, if the process parameters remain the same throughout the drilling, the hole will have positive taper due to the wear of a wire electrode. Advanced micro-hole EDM adjusts the process parameters at different stages to control the hole shape [20]. At the start of drilling, negative polarity (anode for the wire electrode and cathode for the workpiece) is applied to blunt or flatten the tip of an electrode sharpened after micro-hole drilling. This is called electrode dressing. Figures $4(a)$ and $(b)$ show the tip of a $125 \mu \mathrm{m}$ diameter tungsten electrode after the micro-hole drilling and electrode dressing, respectively. A flat end electrode can reduce the positive taper of the drilled hole. Near the end of micro-hole drilling, the gap voltage is increased to enlarge the gap width inside the micro-hole to enable the generation of the negative taper, as is shown in figure $3(b)$. The rounded flow entry, as is shown in figure $3(c)$, can be achieved by using the AFM, which flows abrasive media through the micro-hole under high pressure to round the inlet edge of the micro-hole [21-23]. Both negative tapered hole and rounded flow entry have proven to improve the diesel fuel flow and atomization characteristics and can reduce engine exhaust emissions $[3,13]$. The CMM measurement provides a quantitative method to specify and evaluate the effect of the AFM on micro-hole geometry.

In this paper, the measurement machine setup is first presented. The EDM process parameters and measurement procedure for a micro-hole are then discussed. Measurement results for form and dimension accuracy of the micro-hole are then analyzed. The gauge R\&R of micro-hole characteristics are discussed. Finally, the effect of the AFM on the shape and size of the micro-hole is demonstrated.

\section{Measurement machine setup}

\subsection{Measurement machine}

Measurements of injector micro-holes were conducted in a Werth VideoCheck HA 400 CMM. Figure 5 shows the schematic diagram of the CMM measurement setup using a glass-fiber probe with a ball end tip and a charge coupled device (CCD) optical sensor to measure the ball position. An overview of the experimental setup is shown in figure $6(a)$. The probe is made of glass, and its tip has a spherical ball of $74 \mu \mathrm{m}$ diameter. The ball is connected to a $25 \mu \mathrm{m}$ diameter and $1.5 \mathrm{~mm}$ long glass fiber shank. Connecting to the glass fiber is the $20 \mathrm{~mm}$ long tapered glass shank, which gradually increases the diameter from 25 to about $200 \mu \mathrm{m}$. This is illustrated in the close-up view of the nozzle tip and the glass probe in figure $6(b)$. The ball end tip of the probe in figure $6(b)$ is inside the micro-hole.

Three light sources are available from the inside, top and bottom of the micro-hole, respectively. The light can be transmitted through the glass to illuminate the inside of the micro-hole. On the top is the light around the objective lens. Inside the nozzle, a $1 \mathrm{~mm}$ diameter metal tube with a reflective mirror at the tip delivers the light to the bottom of the hole. The CMM has three axes. The injector with micro-holes is carried by the $X$-and $Y$-axes. The probe is moved up and down by the $Z$-axis. All axes have $0.1 \mu \mathrm{m}$ resolution and are moved by either the manual or the computer-control mode.

A specially designed fixture, which can orient the microhole by three mutually perpendicular and computer-controlled axes, is used to hold the injector.

\subsection{Machine setup}

Three setup procedures are performed: (i) align the axis of probe with the $Z$-axis of the CMM, (ii) align the axis of hole with the axis of the probe and (iii) identify the top datum circle of the hole. 


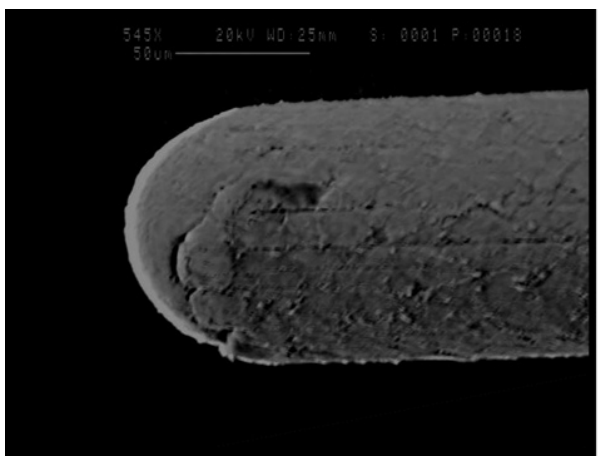

(a)

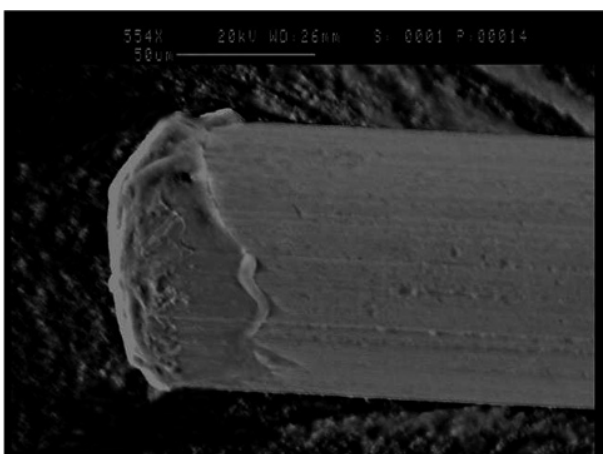

(b)

Figure 4. SEM micrographs of the tip of a tungsten wire electrode: $(a)$ sharpened electrode tip after the EDM stage 2 and $(b)$ blunted electrode tip after the EDM stage 1 (diameter of the wire electrode is $125 \mu \mathrm{m}$ ).

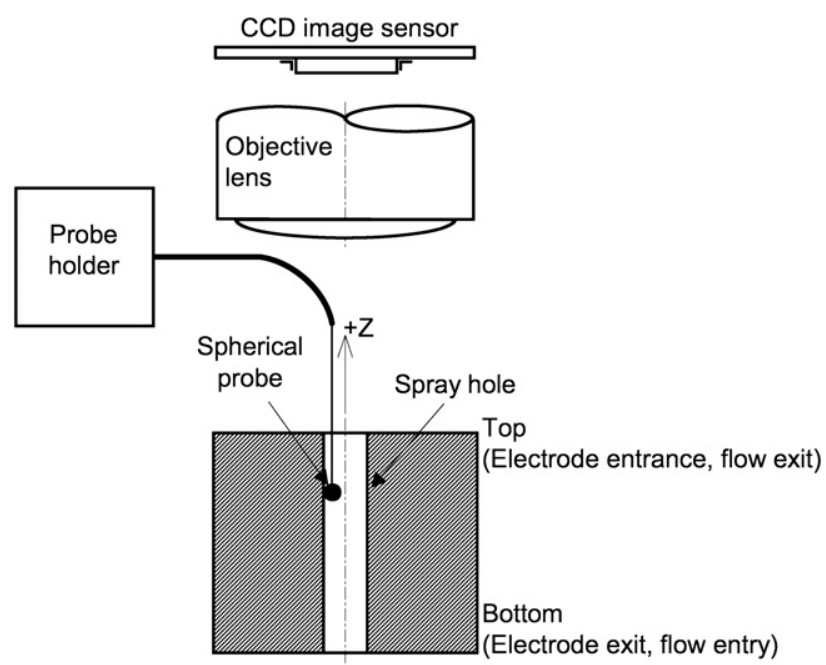

Figure 5. Micro-hole measurement using the combination of optical and contact sensors in a CMM.
A precision ring with a mirror-polished tapered inner surface is used as an artifact to align the axis of probe with the $Z$-axis of the CMM, as is shown in figure 7(a). The alignment is conducted at four positions, $90^{\circ}$ apart from each other, around the circumference of the ring's inner surface. After the probe is aligned with the $Z$-axis of the CMM, the ball tip is moved inside the micro-hole, as is shown in figure $7(b)$, to align the axis of the hole with the axis of the probe. The micro-hole in the injector is oriented to avoid the interference of the probe shank and micro-hole at four positions, $90^{\circ}$ apart from each other, around the circumference of the micro-hole. Since the difference of the radius between the ball and the shank in the probe tip is only $25 \mu \mathrm{m}$, the hole is well aligned if no interference of the shank and the hole is achieved.

After the injector and micro-hole are aligned, the probe is moved to touch the top of the hole to identify the top circle of the hole as the datum for the $Z$-direction. A fine movement of the probe along the $Z$-axis is performed to find the edge of the hole, as is shown in figure $7(c)$. If the ball is above the edge of the hole, as is shown by the probe on the left in figure $7(c)$, the

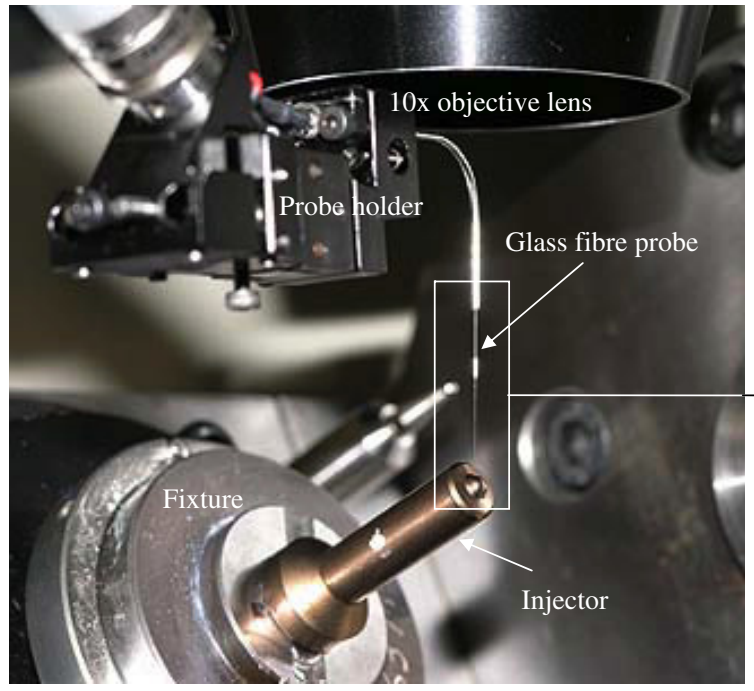

(a)

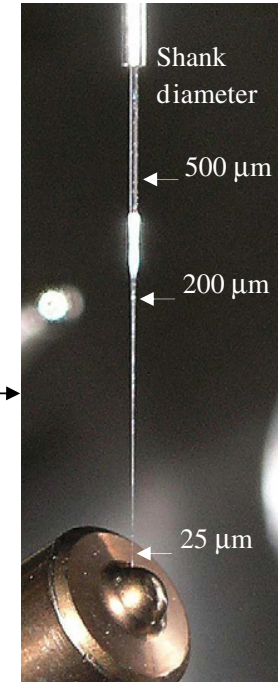

(b)

Figure 6. Setup of micro-hole measurement: $(a)$ overview of the nozzle, probe and optical lens and $(b)$ close-up view for the glass fiber probe. 


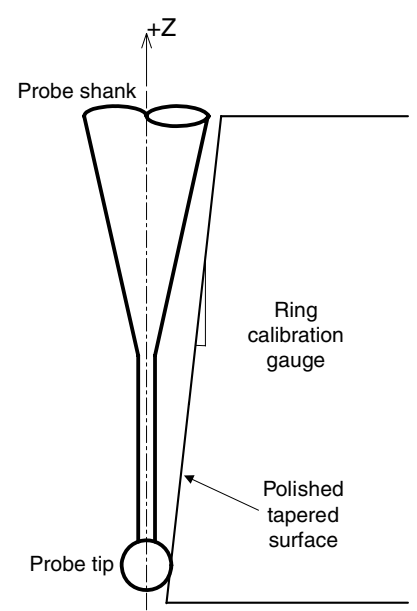

(a)

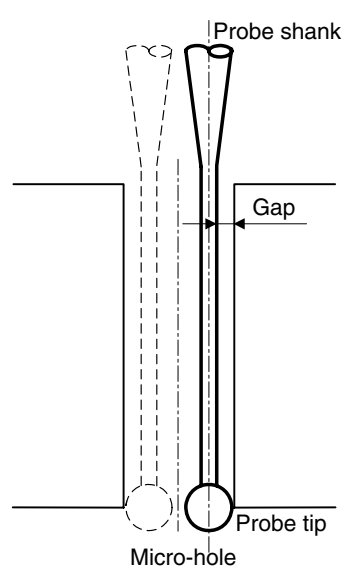

(b)

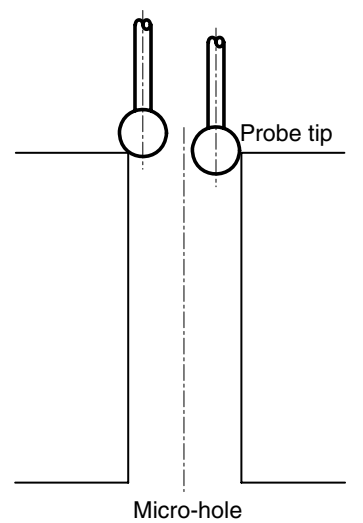

(c)
Figure 7. Three setup procedures: $(a)$ align the probe with the CMM machine $Z$-axis, $(b)$ align the micro-hole with the calibrated probe and $(c)$ locate the top datum circle and reference point of the micro-hole.

whole ball can be observed and the position of the probe needs to be lowered in the $Z$-axis. This procedure is repeated in 12 positions, $30^{\circ}$ apart from each other, around the circumference of the top edge of the hole to find the $Z$-axis datum location. This position is set as the zero for the $Z$-axis in the subsequent measurement.

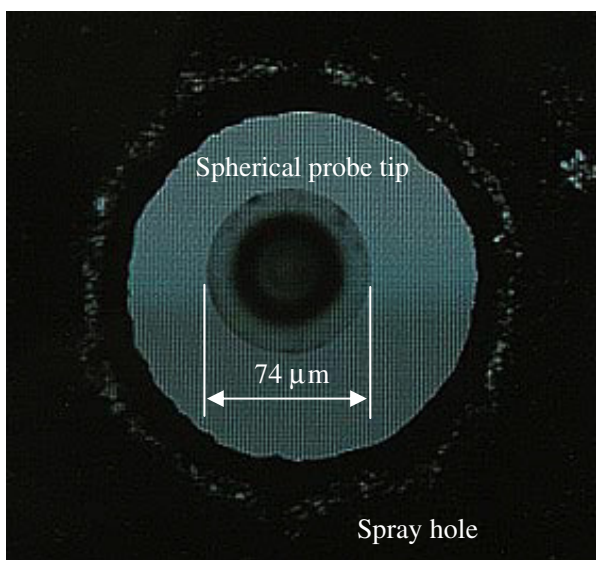

(a)

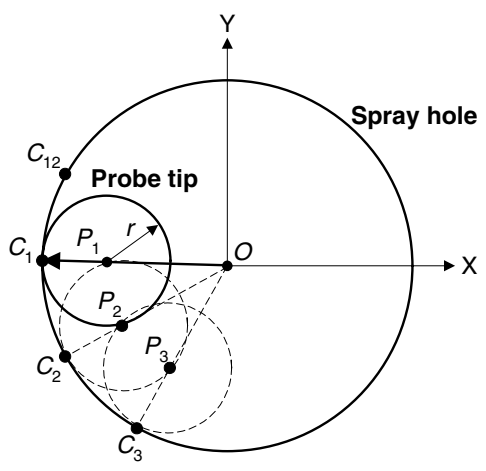

Figure 9. Determination of the contact point between the micro-hole surface and the probe tip.

\subsection{Determining the coordinates of contact points}

The contact point between the ball tip of the probe and the hole surface cannot be detected by the CCD image sensor. Figure $8(a)$ shows the image captured by the CCD when the probe is positioned near the center of the hole. When the probe is moved to contact the hole surface, as is shown in figure $8(b)$, only a portion of the ball near the hole center is visible. The image processing software is utilized to define a rectangular box, as is shown in figure $8(b)$, to enclose the arc region of the ball to find its center position and radius.

Mathematically, as is shown in figure 9 , the point $P_{1}$ can be found using the CMM. The probe is contacted with the hole at 12 locations, $30^{\circ}$ apart from each other, under the same $Z$ position. The centers of the probe tip in the next two contact locations are marked as $P_{2}$ and $P_{3}$ respectively. Sequentially, the probe center from $P_{4}$ to $P_{12}$ can be measured. Using the information of $P_{1}$ to $P_{12}$, the center of the circle $O$ can be found. The vector from the center $O$ to the contact point $C_{1}$ is derived using the following equation:

$$
\overrightarrow{O C_{1}}=\left(r+\left|\overrightarrow{O P_{1}}\right|\right) \frac{\overrightarrow{O P_{1}}}{\left|\overrightarrow{O P_{1}}\right|},
$$

where $r$ is the radius of the probe tip. The contact points $C_{2}$ to $C_{12}$ can be found following the same procedure.

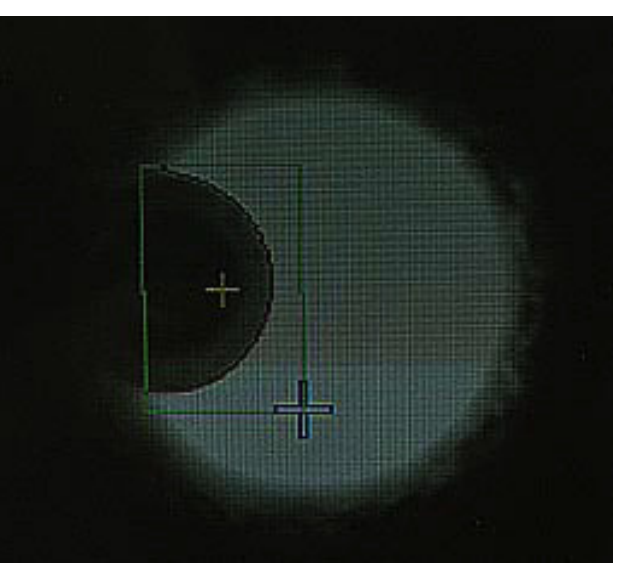

(b)

Figure 8. The measurement of a micro-hole by the spherical probe tip: $(a)$ the spherical probe tip inside a micro-hole and $(b)$ the spherical probe tip in contact with the micro-hole and the user-defined rectangle for arc identification. 
Table 1. Process parameters of three stages in micro-hole EDM.

\begin{tabular}{|c|c|c|c|}
\hline $\begin{array}{l}\text { Stage } \\
\text { Function }\end{array}$ & $\begin{array}{l}1 \\
\text { Electrode } \\
\text { dressing }\end{array}$ & $\begin{array}{l}2 \\
\text { Drilling }\end{array}$ & $\begin{array}{l}3 \\
\text { Penetration }\end{array}$ \\
\hline Drilling depth, $D(\mathrm{~mm})$ & 0.10 & 0.762 & 1.20 \\
\hline $\begin{array}{l}\text { Electrode travel relative to } \\
\text { the hole depth }(\%)\end{array}$ & 11 & 73 & 16 \\
\hline Gap voltage, $V_{\mathrm{g}}(\mathrm{V})$ & 160 & 200 & 230 \\
\hline Polarity & Negative & Positive & Positive \\
\hline
\end{tabular}

The contact points on circles at different $Z$ positions are measured to create an array of contact points to represent the micro-hole.

\section{Micro-hole preparation and measurement procedure}

\subsection{Fabrication of injector micro-holes}

The micro-holes, about $0.9 \mathrm{~mm}$ deep and $160 \mu \mathrm{m}$ in diameter, were drilled using a $127 \mu \mathrm{m}$ diameter tungsten wire electrode. The EDM process parameters vary at three drilling depths, denoted as stages 1,2 and 3. Table 1 lists key EDM process parameters of three stages. Stage 1 is used for electrode dressing. Negative polarity and low gap voltage were applied to blunt the sharp electrode tip, as is illustrated in figure 4, in the first $0.1 \mathrm{~mm}$ of drilling depth, denoted as $D$ in figure 2. Most of the drilling, with $D$ from 0.1 to $0.76 \mathrm{~mm}$, was completed in stage 2 using positive polarity and moderate gap voltage $(200 \mathrm{~V})$. The gap voltage was increased to $230 \mathrm{~V}$ in stage 3 to enlarge the gap width between the electrode and workpiece. This setup generates the negative taper, as is illustrated in figure $3(b)$.

Three micro-holes, machined under an identical EDM process setup, were used in this measurement study.

\subsection{Procedures for measurement}

As is shown in figure 10, the micro-hole was measured using 12 contact points in 12 sections in the $Z$-axis direction. Positions of these 12 contact points, marked by 1 to 12 , in the injector nozzle are illustrated in figure $10(a)$. Point 4 is the closest to and point 3 is the farthest from the injector. Four sections are selected in each stage. As is shown in figure $10(b)$, the spacing in the $Z$-direction of the adjacent sections is about 30 $\mu \mathrm{m}$ in the stage 1 region, machined using negative polarity for electrode dressing. The spacing between adjacent sections increases to $130 \mu \mathrm{m}$ in stage 2 and about $50 \mu \mathrm{m}$ in stage 3 . For each hole, 144 points were measured. These measured points were analyzed to find the form characteristics of micro-holes.

For the gauge R\&R study, the experiment and data analysis were implemented based on standard procedures developed for the measurement system analysis [24]. Three micro-holes were selected for the gauge R\&R study. For the repeatability study, after setting up the reference position for a micro-hole, four repeated measurements were conducted without removing the injector from the fixture. For the reproducibility study, the number of measurement groups is set to two, i.e. the same procedure of three micro-holes with four measurements was repeated twice. In total, $3456(=3 \times$ $2 \times 4 \times 144)$ contact point measurements were conducted in this study.

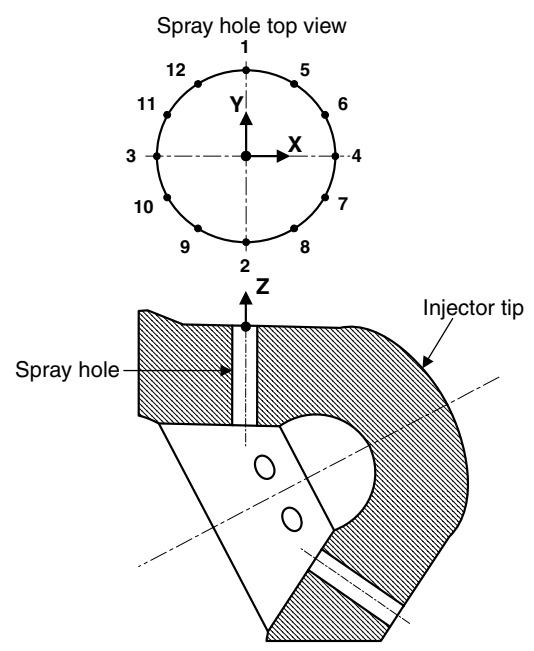

(a)

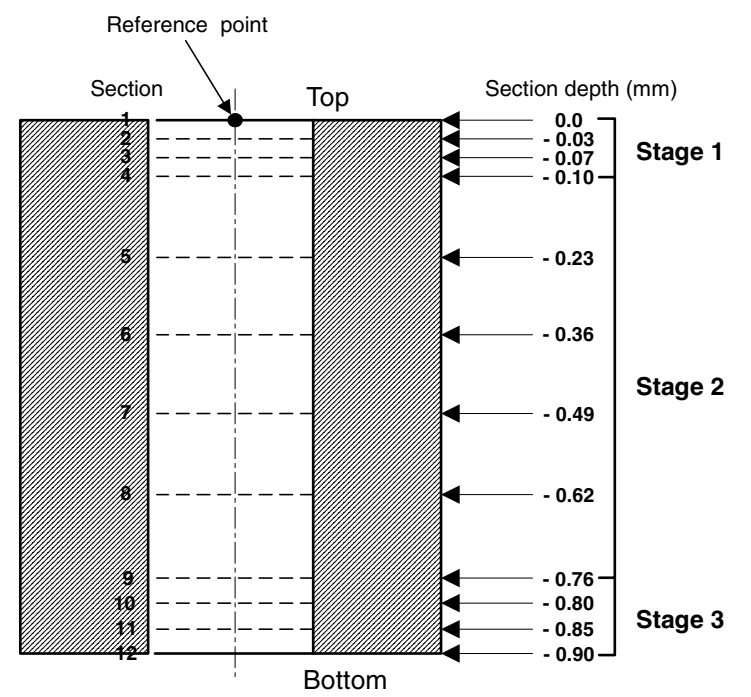

(b)

Figure 10. Shape measurement of micro-holes: $(a)$ orientation of the coordinate system and locations of selected measurement points and $(b)$ depths of different sections according to the three EDM stages.

\subsection{Characteristics of micro-holes}

Five features, cylindricity, diameter, roundness, taper and straightness, are used to characterize the micro-holes.

- Cylindricity. The cylindricity is defined as a tolerance zone bounded by two coaxial cylinders between which the measured cylinder must lie. The least-square (LS) fitting method [25] is used to calculate the cylindricity.

- Diameter. The diameter of the LS fitted cylinder is used to represent the hole size.

- Roundness. The 12 points in a section are analyzed to calculate the roundness. The roundness versus the depth of circle in the micro-hole is investigated.

- Straightness. The measured points 1, 2, 3 and 4, as are defined in figure $10(a)$, of the 12 sections are used to calculate the straightness. The LS fitted line of measurement points in 12 sections is used to represent the straightness at points 1, 2, 3 and 4 of the micro-hole. 
Table 2. Measurement results on three micro-holes before and after the abrasive flow machining.

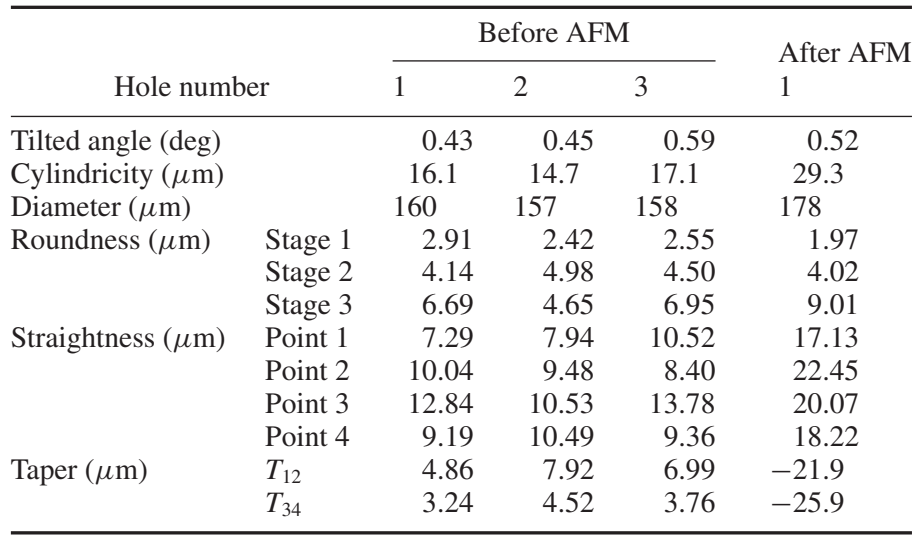

- Taper. Two pairs of lines 1,2 and 3,4 determine two taper values of the micro-hole. The taper is the difference in distances between these two lines at the entrance and exit ends of the micro-hole, i.e. difference in the size of the hole. Positive taper, as is shown in figure 3(a), is defined to have positive value of the taper.

A parameter called tilted angle is used to determine the accuracy of the alignment. The tilted angle is defined as the angle between the axis of the cylinder representing the microhole and the vector perpendicular to the plane representing the 12 measurement points in a section.

\subsection{Gauge $R \& R$}

For each measurement group, the range $R$ and average $\bar{X}$ of measured dimension characteristics were identified for each of the three micro-holes. The standard deviation for repeatability, $\sigma_{\text {repeatability, is [24] }}$

$$
\sigma_{\text {repeatibility }}=\frac{\bar{R}}{d_{2}^{\prime}},
$$

where $\bar{R}$ is the average of range $R$ for both measurement groups and $d_{2}^{\prime}$ is a coefficient depending on the number of trials, samples and measurement groups [24]. In this study, the number of trials is four and the number of samples times the number of measurement groups is six $(=3 \times 2)$. The value of $d_{2}^{\prime}$ is 2.09 . is [24]

The standard deviation for reproducibility, $\sigma_{\text {reproducibility, }}$

$$
\sigma_{\text {reproducibility }}=\sqrt{\left(\frac{R_{0}}{d_{2}^{\prime \prime}}\right)^{2}-\frac{\sigma_{\text {repeatability }}^{2}}{n r}},
$$

where $R_{0}$ is the range of the average of $\bar{X}$ for both measurement groups, $n$ is the number of samples, $r$ is the number of trials and $d_{2}^{\prime \prime}$ is again dependent on the number of measurement setup. In this study, the number of measurement groups is 2 and the number of range calculations is 1 . The value of $d_{2}^{\prime \prime}$ is 1.41 .

The standard deviation for the gauge $\mathrm{R} \& \mathrm{R}, \sigma_{\mathrm{R} \& \mathrm{R}}$, is [24]

$$
\sigma_{\mathrm{R} \& \mathrm{R}}=\sqrt{\sigma_{\text {repeatability }}^{2}+\sigma_{\text {reproducibility }}^{2}} .
$$

The value of $5.15 \sigma_{\mathrm{R} \& \mathrm{R}}$ is commonly used to represent $99 \%$ population of measurements for a normal distribution. The ratio $\sigma_{\mathrm{R} \& \mathrm{R}} / \sigma_{\text {part }}$ is used to assess the measurement system capability, where $\sigma_{\text {part }}$ is the standard deviation for part. For a capable measurement system, $\sigma_{\mathrm{R} \& \mathrm{R}} / \sigma_{\text {part }}$ needs to be smaller than $10 \%$ [24]. In practical applications, $30 \%$ of $\sigma_{\mathrm{R} \& \mathrm{R}} / \sigma_{\text {part }}$ could be acceptable. The part standard deviation under the $10 \%$ and $30 \%$ criteria can be calculated from $\sigma_{\mathrm{R} \& \mathrm{R}}$.

The value of $5.15 \sigma_{\text {part }}$ is defined as the capability tolerance of a measurement system. The capability tolerance is used to assess the capability of the CMM for micro-hole measurements. Values for capability tolerance are valuable for product engineers to specify micro-hole tolerances that are measurable and for metrology engineers to quantify the measurement capability and further improve the capability of gauges.

\section{Measurement results}

Table 2 summarizes the tilted angles and five measured characteristics of three micro-holes. The tilted angle is small, ranging from 0.4 to $0.6^{\circ}$. It demonstrates the good alignment of the micro-hole with the CMM Z-axis and ensures that the 12 data points in sections perpendicular and parallel to the hole axis can be used to calculate the roundness and straightness of the micro-hole, respectively. The five measured characteristics of three micro-holes are discussed as follows.

- Cylindricity. The cylindricity of three micro-holes is 16.1, 14.7 and $17.1 \mu \mathrm{m}$, about $10 \%$ of the cylinder size.

- Diameter. The diameters of three micro-holes are 160, 157 and $158 \mu \mathrm{m}$. These holes were drilled using a $127 \mu \mathrm{m}$ diameter tungsten wire electrode. The average gap between the wire and workpiece is about $15 \mu \mathrm{m}$. The variation of diameter for the 12 sections of micro-holes is shown in figure 11. Without considering the skewness of the hole axis and roundness of the section, figure 11 gives a rough representation of the hole shape. The largest diameter of the hole occurs at $0.35 \mathrm{~mm}$ depth, near the middle of the micro-hole. The smallest diameter of the hole is inside the hole at $0.85 \mathrm{~mm}$ depth. This narrow section of the hole is likely contributed by the rounding or sharpening of the electrode tip, as is shown in figure 4(a), near the end of hole drilling. The use of large gap voltage in stage 3 does enlarge the inside diameter of the hole where the electrode exits the micro-hole. The difference between the maximum and minimum diameters 


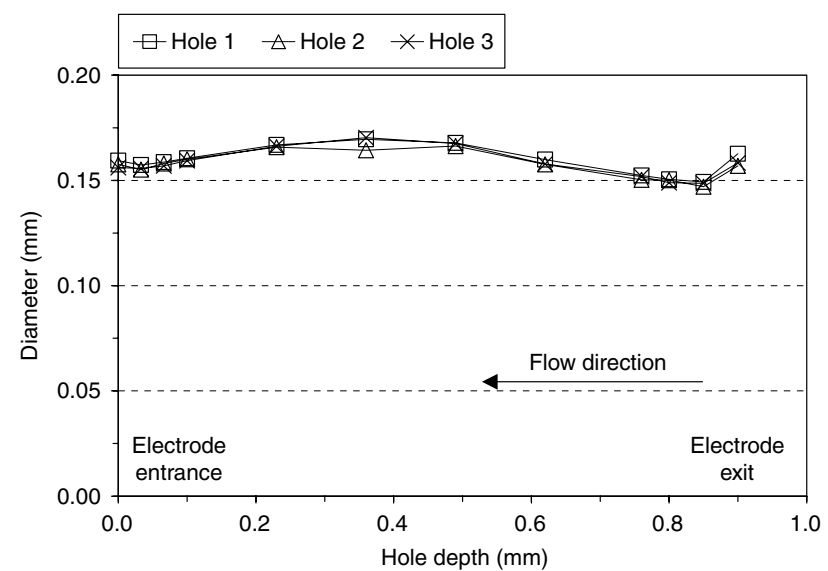

Figure 11. Diameter of 12 measurement sections in three micro-holes.

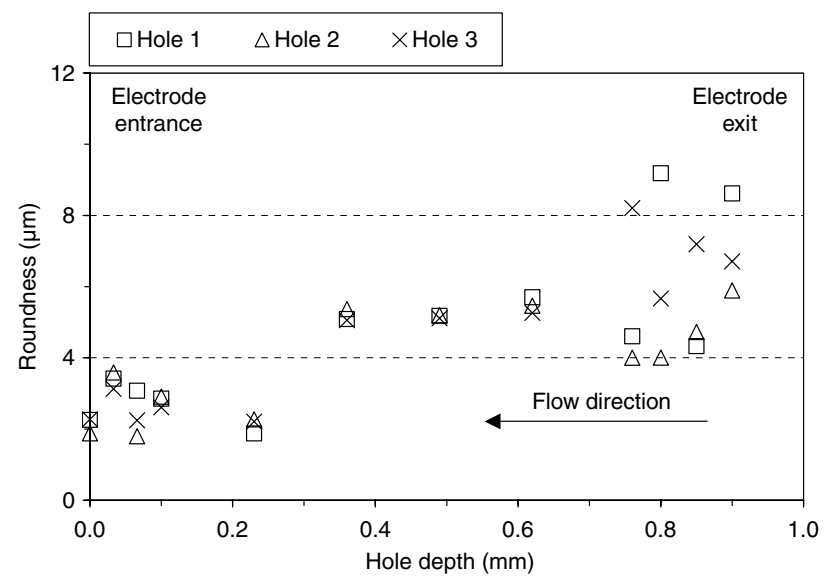

Figure 12. Roundness of 12 measurement sections in three micro-holes.

of the micro-hole is about $30 \mu \mathrm{m}$. At the electrode entry side, the hole diameter is also small, which is likely due to the low gap voltage in electrode dressing in stage 1 . The variation among three holes is not large.

- Roundness. The roundness of three holes is shown in figure 12. The EDM process parameters in three stages greatly affect the roundness. The roundness is higher deeper inside the hole. In stage 1, the roundness is small, about 2.0 to $3.5 \mu \mathrm{m}$. In stage 2 , the roundness is consistent at about $4.5 \mu \mathrm{m}$. In stage 3 , the variation of roundness becomes very large, ranging from 4.0 to $8.5 \mu \mathrm{m}$. Such a large variation in roundness measurement can be attributed to three factors: (i) uneven wear of electrode near the end of hole drilling, (ii) rough surface due to the large gap voltage in stage 3 and (iii) large measurement uncertainty inside the hole. The measurement uncertainty will be discussed in the following section.

- Straightness. The straightness at points 1, 2, 3 and 4 (figure 10(a)) of three micro-holes are listed in table 2. The straightness ranges from 7 to $14 \mu \mathrm{m}$. Point 3 has consistently higher straightness than the other three points. During micro-hole EDM, point 3 is located at the bottom

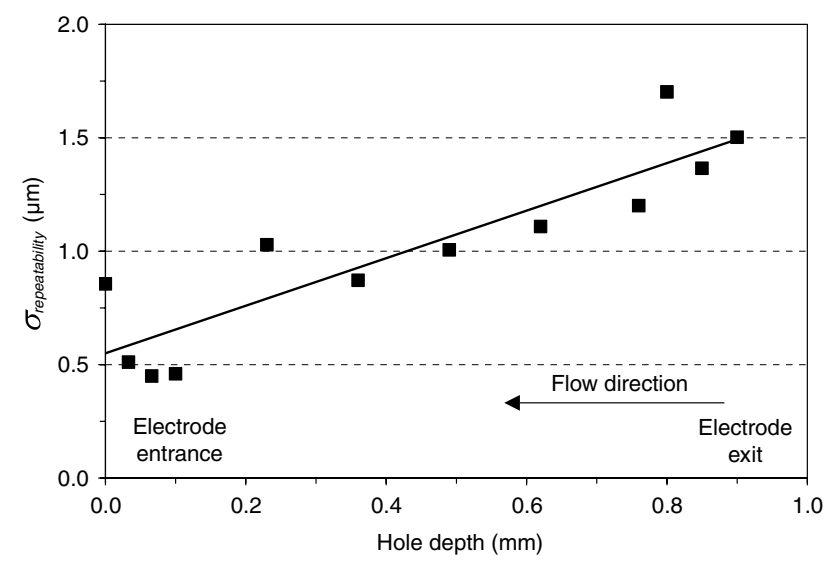

Figure 13. $\sigma_{\text {repeatability }}$ of roundness for 12 measurement sections.

where the debris accumulated due to gravity. Since deionized water was supplied by dribbling and debris cannot be flushed out effectively at point 3 , it is likely to be the cause of poor straightness.

- Taper. Tapers $T_{12}$ and $T_{34}$, as listed in table 2, range from 3 to $8 \mu \mathrm{m}$. Although point 3 has high straightness, the taper $T_{34}$ is consistently lower than $T_{12}$. The taper is also lower than the straightness. All tapers are positive, which is common in micro-holes drilled by the EDM.

\section{Gauge R\&R for micro-hole measurements}

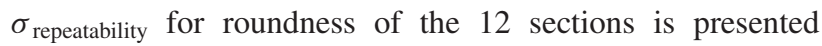
in figure 13. $\sigma_{\text {repeatability }}$ gradually deteriorates inside the hole, increasing from 0.5 to $1.7 \mu \mathrm{m}$. This is due to the limited accuracy of the vision system for measurements of ball positions deep inside the micro-hole. Large $\sigma_{\text {repeatability }}$ contributes to the large variation of roundness in stage 3 , as is shown in figure 12.

$\sigma_{\text {repeatability, }} \sigma_{\text {reproducibility }}$ and $\sigma_{\mathrm{R} \& \mathrm{R}}$ of cylindricity, diameter, roundness, straightness and taper measurements are summarized in table 3. $\sigma_{\text {repeatability }}$ represents the repeatability of the CMM for measuring a specific hole characteristic. The zero value for $\sigma_{\text {reproducibility }}$ implies that the gauge variation is larger than the measurement group variation. $\sigma_{R \& R}$ is the index of measurement capability of the gauge for a specific feature. The capability tolerance (CT) of the CMM for $\sigma_{\mathrm{R} \& \mathrm{R}} / \sigma_{\text {part }}<30 \%$ and $10 \%$ for each of the hole characteristics are summarized in table 3 . The CT values specify the part tolerance that can be capably measured by the CMM. For cylindricity, the measurement capability is not very good: capable of only $70 \mu \mathrm{m}$ and marginally capable of $23 \mu \mathrm{m}$. For diameter, the measurement is capable of $15 \mu \mathrm{m}$ and marginally capable of $5 \mu \mathrm{m}$. For roundness, the gauge is more capable in stage 1 (outside the hole) than in stage 3 (inside the hole). This is consistent with the trend of roundness $\sigma_{\text {repeatability }}$ in figure 13. The gauge capability is good for straightness, but poor for taper. Results in table 3 provide a guideline for designers to specify tolerances for the diesel fuel injector micro-holes and for metrology engineers to further improve the measurement capability. 
Table 3. Gauge R\&R and capability tolerance for the CMM micro-hole measurement.

\begin{tabular}{|c|c|c|c|c|c|c|}
\hline & & \multirow[b]{2}{*}{$\sigma_{\text {repeatability }}(\mu \mathrm{m})$} & \multirow[b]{2}{*}{$\sigma_{\text {reproducibility }}(\mu \mathrm{m})$} & \multirow[b]{2}{*}{$\sigma_{\mathrm{R} \& \mathrm{R}}(\mu \mathrm{m})$} & \multicolumn{2}{|c|}{ Capability tolerance $(\mu \mathrm{m})$} \\
\hline \multicolumn{2}{|c|}{ Dimension type } & & & & $\sigma_{\mathrm{R} \& \mathrm{R}} / \sigma_{\text {part }}<0.3$ & $\sigma_{\mathrm{R} \& \mathrm{R}} / \sigma_{\text {part }}<0.1$ \\
\hline Cylindricity & & 1.36 & 0 & 1.36 & 23.4 & 70.2 \\
\hline Diameter & & 0.30 & 0 & 0.30 & 5.15 & 15.5 \\
\hline \multirow[t]{3}{*}{ Roundness } & Stage 1 & 0.60 & 0.12 & 0.63 & 10.8 & 32.4 \\
\hline & Stage 2 & 0.90 & 0.08 & 0.91 & 15.6 & 46.9 \\
\hline & Stage 3 & 1.44 & 0.04 & 1.45 & 24.9 & 74.7 \\
\hline Straightness & & 0.36 & 0.14 & 0.39 & 6.70 & 20.1 \\
\hline Taper & & 1.51 & 0.54 & 1.60 & 27.5 & 82.5 \\
\hline
\end{tabular}

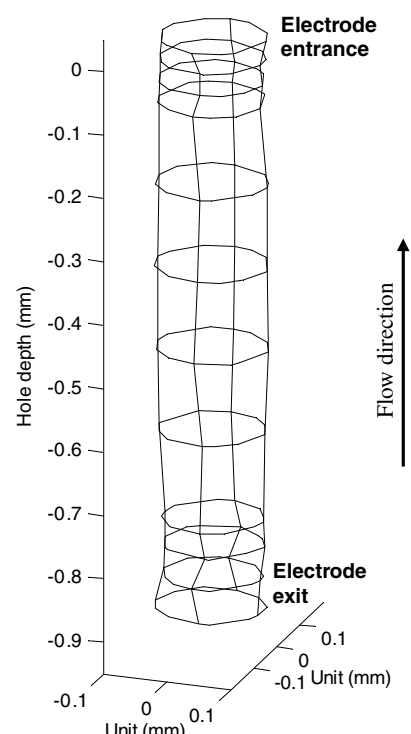

(a)

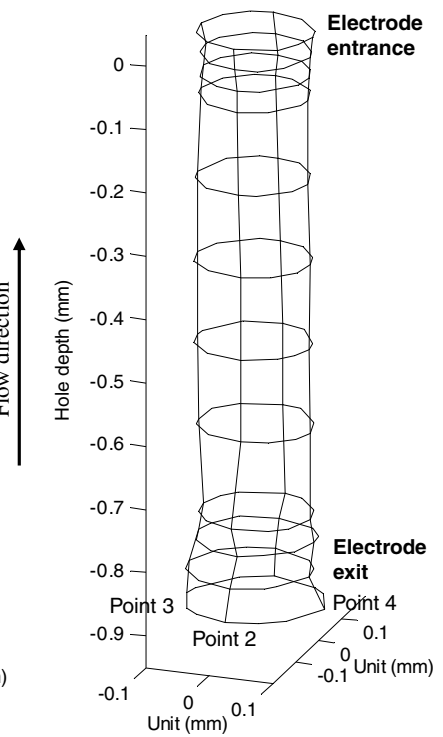

(b)
Figure 14. 3D wireframe representation of hole 1: (a) before AFM and (b) after AFM.

\section{Effect of the AFM on micro-hole geometry}

The AFM is a non-traditional machining process applied to improve the surface condition and round the flow entry (electrode exit) of the micro-hole [21]. The abrasive media, which are a mixture of abrasive grit and a semi-solid carrier [22], flow through the micro-hole at high pressure to round the inlet or flow entry edge and improve the surface roughness. In this study, $\mathrm{SiC}$ abrasive with a nominal size of $0.015 \mathrm{~mm}$ was used in an ExtrudeHone machine. The flow pressure and process cycle time were set at $27.6 \mathrm{MPa}$ and $25 \mathrm{~s}$, respectively.

The 3D wireframe representations of measured points for hole 1 before and after the AFM process are shown in figures 14(a) and (b), respectively. The fuel inlet (electrode exit) edge of the hole has been enlarged and rounded after the AFM. The rounding is uneven around the hole circumference of the hole inside edge. More material is removed at point 3, which is away from the injector tip. The flow pattern of high viscosity media in the AFM affects the material removal rate around the circumference of the hole edge. Such an effect can be quantified using the micro-hole measurement technique developed in this study.

The cylindricity, diameter, roundness, straightness and taper of hole 1 machined after the AFM are listed in the last

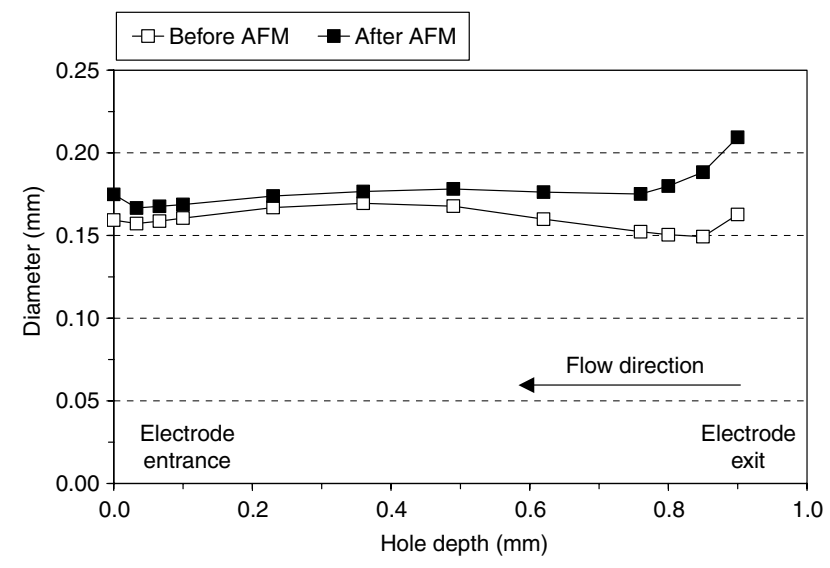

Figure 15. Effects of the AFM on the micro-hole diameter.

column of table 2. Due to the rounding of the hole inside the edge, the cylindricity, diameter and straightness are all increased. The roundness is improved in the stages 1 and 2 regions, but worsened in the stage 3 region (near the hole inside edge). The taper becomes negative, which demonstrates the effect of the AFM to alter the hole geometry.

The diameter of hole 1 before and after AFM for 12 sections in the $Z$-axis is shown in figure 15 . The diameter after the AFM is increased by about 10 to $25 \mu \mathrm{m}$ in stages 1 and 2 regions. In the stage 3 region, the hole diameter is increased by about 35 to $50 \mu \mathrm{m}$.

\section{Concluding remarks}

In this study, the form measurement and gauge $R \& R$ of micro-holes were conducted. Geometric (cylindricity, roundness, straightness and taper) and dimensional (diameter) characteristics of three $160 \mu \mathrm{m}$ diameter micro-holes were measured. Effects of the EDM process parameters on hole geometry were correlated. Capable tolerance specifications measured using the CMM were calculated. The change of hole geometry, particularly the rounding of hole inside edge on one side and enlarging of the hole size, using the AFM was revealed using the micro-hole measurement technique.

The measurement capability of the CMM for microhole measurement is certainly limited, compared to that of large hole measurement. Further improvements of measurement technology, both in imaging and in scanning contact probe, will further advance the gauge $R \& R$. Using the scanning probe, more points can be acquired for accurate roundness, straightness, taper, cylindricity and the overall 
form measurement of micro-holes. The measured data points can be processed to create a $3 \mathrm{D}$ representation of the microhole and to further understand and correlate the effects of hole machining (laser, EDM, etc) and post-machining (AFM) processes on the hole geometry, spray pattern and engine emissions. Such a link between manufacturing and product engineering is important for the development of future clean diesel combustion technology.

\section{References}

[1] Masuzawa T, Hamasaki Y and Fujino M 1993 Vibroscanning method for nondestructive measurement of small holes Ann. CIRP 42 589-92

[2] Masuzawa T, Tsukamoto J and Fujino M 1989 Drilling of deep microholes by EDM Ann. CIRP 38 195-8

[3] Giedl R, Helml H J, Wagner F X and Wild M J 2003 Geometrical aspects of laser-drilled high precision holes for flow control applications Proc. SPIE 5063, 4th Int. Symp. on Laser Precision Microfabrication (Bellingham, USA, 2003) pp 389-94

[4] Ahmed M S and Duffield A 1989 Deep hole drilling using ECM SME Tech Paper MS89-816 1-16

[5] Iwata K and Moriwaki T 1981 Basic study of high speed micro deep drilling Ann. CIRP 30 27-30

[6] Adler U 1994 Diesel Fuel Injection (Stuttgart: Robert Bosch $\mathrm{GmbH})$

[7] Hebbar R R 1992 Micro-hole drilling by electrical discharge machining PhD Dissertation Purdue University

[8] Morita H, Ohyama S and Mohri N 2000 Electrical discharge device with direct drive method for thin wire electrode $S A E$ Tech Paper 2000-01-1085

[9] Holt D J 2004 The Diesel Engine (Warrendale: SAE) pp 257-65

[10] Johnson T V 2003 Diesel emission control in review-the last 12 months SAE Tech Paper 2003-01-0039

[11] Kim B J, Masuzawa T, Fujita H and Tominaga A 1998 Dimensional measurement of microholes with silicon-based micro twin probes Proc. IEEE Micro Electro Mechanical Systems (MEMS) (Heidelberg, Germany, 1998) pp 334-9

[12] Yamamoto M, Kanno I and Aoki S 2000 Profile measurement of high aspect ratio micro structures using tungsten carbide micro cantilever coated with PZT thin films Proc. IEEE Micro Electro Mechanical Systems (MEMS) (Miyazaki, Japan, 2000) pp 217-22

[13] Diver C, Atkinson J, Helml H J and Li L 2004 Micro-EDM drilling of tapered holes for industrial applications J. Mater. Process. Technol. 149 296-303

[14] Masuzawa T, Kim B J, Bergaud C and Fujino M 1997 Twin-probe vibroscanning method for dimensional measurement of microholes Ann. CIRP $46437-40$

[15] Kim B J, Masuzawa T and Bourouina T 1999 The vibroscanning method for the measurement of micro-hole profiles Meas. Sci. Technol. 10 697-705

[16] Lebrasseur E, Pourciel J B, Bourouina T, Masuzawa T and Fujita H 2002 A new characterization tool for vertical profile measurement of high-aspect-ratio microstructures J. Micromech. Microeng. 12 280-5

[17] Pourciel J B, Lebrasseur E, Bourouina T, Masuzawa T and Fujita H 2001 Microsystem tool for microsystems characterization profile measurement of high aspect-ratio microstructures Proc. SPIE 4592, Device and Process Technologies for MEMS and Microelectronics II (Adelaide, Australia, 2001) pp 244-51

[18] Pourciel J B, Jalabert L and Masuzawa T 2003 Profile and surface measurement tool for high aspect-ratio microstructures JSME Int J. C 46 916-22

[19] Christoph R 2004 Multisensor coordinate metrology: flexible measurements of form size and location VDI-Ber. 1860 157-63

[20] Kao C C and Shih A J 2006 Sub-nanosecond monitoring of micro-hole electrical discharge machining pulses and modeling of discharge ringing Int. J. Mach. Tools Manuf. 46 1996-2008

[21] Stackhouse J 1993 Abrasive flow machining SME Tech Paper MR93-148 1-15

[22] Loveless T R, Williams R E and Rajurkar K P 1994 Study of the effects of abrasive-flow finishing on various machined surfaces J. Mater. Process. Technol. 47 133-51

[23] Perry W B 1986 Abrasive flow machining principles and practices Nontraditional Machining Conf. Proc. (Cincinnati, USA, 1986) pp 121-7

[24] Automotive Industry Action Group 1990 Measurement Systems Analysis Reference Manual 1st edn (Southfield, MI: AIAG)

[25] Osborne M R 1985 Finite Algorithms in Optimization and Data Analysis (Chichester: Wiley) 